This item was submitted to Loughborough's Research Repository by the author.

Items in Figshare are protected by copyright, with all rights reserved, unless otherwise indicated.

\title{
Evidence for the microwave effect during the annealing of zinc oxide
}

\section{PLEASE CITE THE PUBLISHED VERSION}

http://onlinelibrary.wiley.com/journal/10.1111/(ISSN)1551-2916

\section{PUBLISHER}

(c) The American Ceramic Society

\section{VERSION}

SMUR (Submitted Manuscript Under Review)

\section{LICENCE}

CC BY-NC-ND 4.0

\section{REPOSITORY RECORD}

Binner, J.G.P., Jianxin Wang, Bala Vaidhyanathan, N. Joomun, J. Kilner, G. Dimitrakis, and T.E. Cross. 2007. "Evidence for the Microwave Effect During the Annealing of Zinc Oxide". figshare. https://hdl.handle.net/2134/3029. 
This item was submitted to Loughborough's Institutional Repository by the author and is made available under the following Creative Commons Licence conditions.

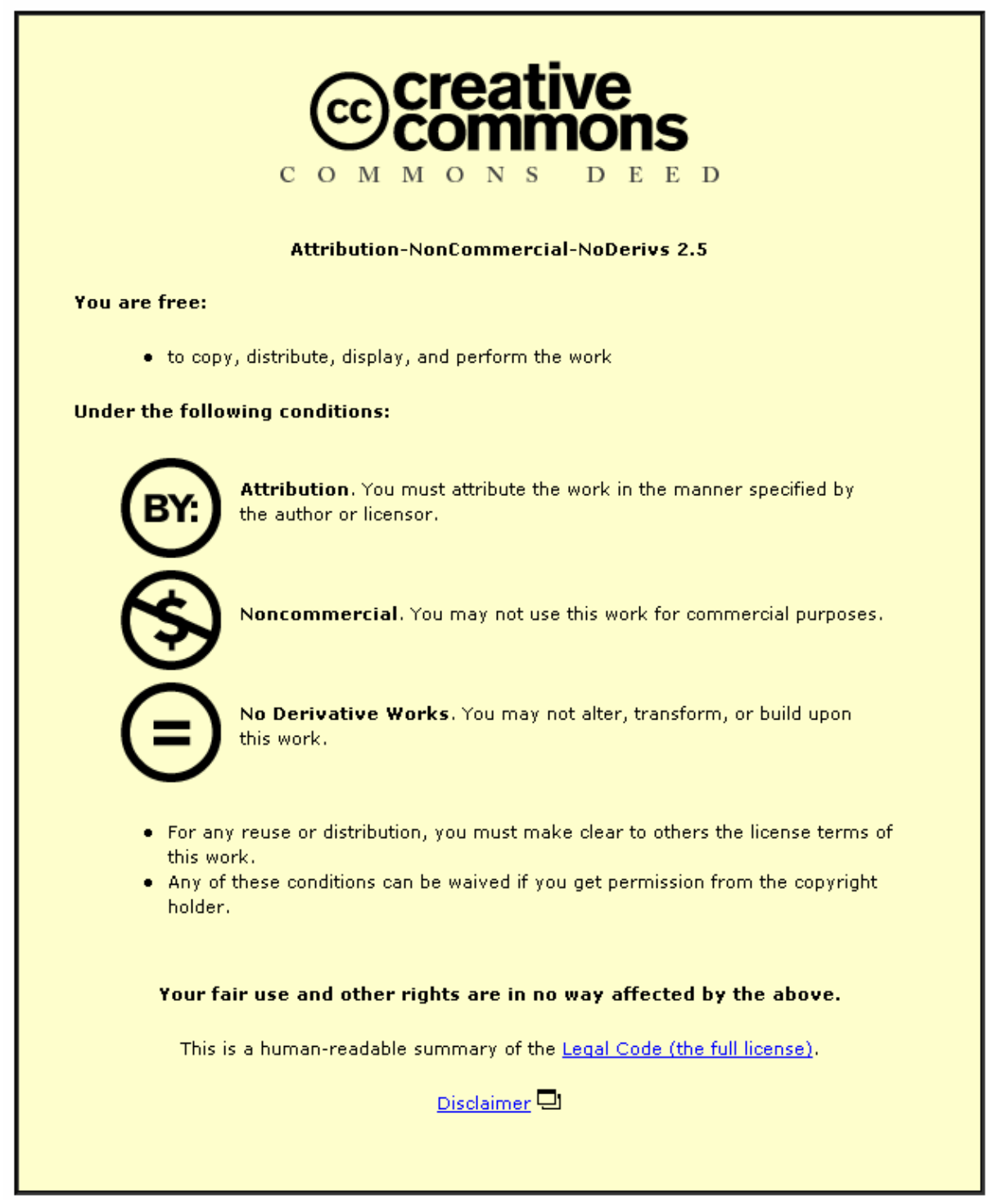

For the full text of this licence, please go to: http://creativecommons.org/licenses/by-nc-nd/2.5/ 


\section{journal}

\section{EVIDENCE FOR THE MICROWAVE EFFECT DURING THE ANNEALING OF ZINC OXIDE}

\begin{tabular}{|r|l|}
\hline Journal: & Journal of the American Ceramic Society \\
\hline Manuscript ID: & JACERS-21594.R1 \\
\hline Manuscript Type: & Article \\
\hline Author: & n/a \\
\hline Complete List of Authors: & $\begin{array}{l}\text { Binner, Jon; Loughborough University, IPTME } \\
\text { Wang, Jianxin; Loughborough University, IPTME } \\
\text { Vaidhyanathan, Bala; Loughborough University, IPTME } \\
\text { Joomun, Nazim; Imperial College, Materials } \\
\text { Kiner, John; Imperial College } \\
\text { Dimitrakis, Georgios; Nottingham University, Electrical \& Electronic } \\
\text { Engineering } \\
\text { Cross, Tom; Nottingham University, Electrical \& Electronic } \\
\text { Engineering }\end{array}$ \\
\hline \hline Keywords: & annealing, microwaves, zinc oxide \\
\hline
\end{tabular}

\section{5) ScholarONE" \\ Manuscript Central}




\title{
EVIDENCE FOR THE MICROWAVE EFFECT DURING THE ANNEALING OF ZINC OXIDE
}

\author{
J. Binner* ${ }^{1}$, J. Wang*², B. Vaidhyanathan*, N. Joomun ${ }^{\dagger}$, J. Kilner ${ }^{\dagger}$, G. Dimitrakis ${ }^{*}$ and T.E. Cross ${ }^{\ddagger}$ \\ * IPTME, Loughborough University, Loughborough, LE11 3TU, UK \\ ${ }^{\dagger}$ Department of Materials, Imperial College, London, SW7 2AZ, UK \\ ${ }^{\star}$ School of Electrical \& Electronic Engineering, University of Nottingham, Nottingham, NG7 2RD, UK
}

\begin{abstract}
A microwave/conventional hybrid furnace has been used to anneal virtually fully dense zinc oxide ceramics under pure conventional and a microwave/conventional hybrid heating regime with a view to obtaining evidence for the 'microwave effect' during the resulting grain growth. In each case it was ensured that each sample within a series had an identical thermal history in terms of its temperature/time profile. The results showed that grain growth was enhanced during hybrid heating compared to pure conventional heating; the greatest enhancement, a factor of $\sim 3$ increase in average grain size, was observed in the range $1100-1150^{\circ} \mathrm{C}$. The grain growth exponent decreased from 3 during conventional heating to 1.4 during hybrid heating in this temperature range, suggesting an acceleration of the diffusional processes involved. Temperature gradients within the samples were found to be too small to explain the results. This suggests that clear evidence has been found to support the existence of a genuine 'microwave effect'.
\end{abstract}

\section{INTRODUCTION}

Many investigators have reported unexpected effects resulting from the use of microwave radiation as an alternative energy source during the processing of materials. This has included apparent evidence for accelerated kinetics for a range of processes in ceramic, polymeric and organic systems $[1,2,3,4,5,6$, $7,8,9,10]$; enhanced sintering of ceramic powder compacts, including lower sintering temperatures $[11,12]$; and reduced activation energies [1,2,3,11]. It is now generally, though not unanimously, accepted that a 'microwave effect' exists, though recent research on the sintering of ceramics involving the use of a single microwave/conventional hybrid furnace appears to have provided extremely clear evidence for its existence [13]. In a parallel study to the current work, three ceramics with different microwave absorption characteristics were sintered under pure conventional and a range of microwave/conventional hybrid heating regimes using exactly the same temperature/time profile. Both the measured final densities of the samples and the use of a dilatometer showed that the presence of microwaves enhanced densification, with higher microwave power levels, finer particle sizes and, particularly, greater microwave absorption by the ceramic, resulting in greater enhancement. The largest effect occurred at temperatures that represented the early to intermediate stage of sintering; for both submicron and micron powder $\mathrm{ZnO}$ samples the increase in densification was equivalent to approximately a $100^{\circ} \mathrm{C}$ higher sintering temperature. A smaller size of effect was observed for yttriadoped zirconia ceramics, which have a lower microwave absorption, whilst for the alumina, a very poor microwave absorber at $2.45 \mathrm{GHz}$, only an extremely small, but nevertheless repeatable, increase in density was observed. These effects could not be accounted for by the presence of temperature gradients of sufficient magnitude, a potential cause of the effect, within the specimens. Two separate techniques based on optical thermometry and a thermal imaging camera both failed to detect any gradients that

\footnotetext{
${ }^{1}$ Corresponding author

${ }^{2}$ Now with Southwestern Jiaotong University, China
} 
were larger than approximately $10^{\circ} \mathrm{C}$ between the centre and edge of the samples, a seventh of the size required to explain the results.

In the present work, the same microwave/conventional hybrid sintering furnace outlined above has been used to investigate the effect of the fraction of microwave power used during hybrid and pure conventional heating on grain growth in $>98 \%$ dense zinc oxide ceramics, again using identical temperature/time profiles for each series of experiments.

\section{EXPERIMENTAL}

A submicron zinc oxide ( $\mathrm{ZnO})$ powder (99.9\% purity, Sigma Aldrich, UK) was used to produce disks measuring $13 \mathrm{~mm}$ diameter by $5 \mathrm{~mm}$ thickness by uniaxial pressing using poly(ethylene glycol)-block poly(prolylene glycol)-block poly(ethylene glycol) binder (Sigma Aldrich). The green densities were $58 \%$ of theoretical. A hole was drilled into the centre of one face of each green disk to accommodate the optical thermometer temperature measurement probe described below and then they were sintered using two-stage sintering with pure conventional heating. Two-stage sintering is a new approach developed by Chen and Wang [14], the aim is to enable the retention of a fine grain size whilst achieving notionally full densification. Based on preliminary work, this involved heating the disks at $20 \mathrm{C} \mathrm{min}^{-1}$ to an initial temperature (T1) of $850^{\circ} \mathrm{C}$ and then immediately cooling to the lower temperature (T2) of $820^{\circ} \mathrm{C}$ as fast as the furnace was capable. The samples were then held at this lower temperature for 15 hrs before furnace cooling back to room temperature. As a result of this sintering schedule, all of the disks used in the current work were $>98.4 \%$ of theoretical density and had an average grain size of $\sim 0.6 \mu \mathrm{m}$.

The disks were subsequently annealed in a single conventional/microwave hybrid furnace for 1,3 or $5 \mathrm{hrs}$ at $900,1000,1100,1150$ or $1200^{\circ} \mathrm{C}$ using either pure conventional heating or hybrid heating involving $1 \mathrm{~kW}$ of $2.45 \mathrm{GHz}$ microwave power and a balance of conventional heat sufficient to achieve an identical temperature/time profile, figure 1 . Note that all the samples were held at $500^{\circ} \mathrm{C}$ for 1 hour at the beginning of each annealing run to ensure that thermal equilibrium was reached before the temperature was increased to the final value chosen. This minimised the magnitude of any temperature gradients developed.

Throughout the work, the temperature was controlled using a Luxtron optical thermometer (M10, Luxton Corporation, USA) inserted into the narrow hole drilled into the centre of the flat face of each sample such that the temperature was measured at the centre of the body. The temperature at the edge of the samples was also monitored using a second optical thermometer, this allowed the temperature gradient across each sample to be determined, figure 2 . The radiation from the heating elements was shielded via the use of a non-metallic, very low dielectric loss ceramic tube around the optical thermometers to achieve accurate temperature measurement. The accuracy of the measurements had been independently assessed using a separate series of measurements involving the melting point of vanadium pentoxide and found to be $\pm 3^{\circ} \mathrm{C}[15]$.

Green sample densities were determined by simple measurement of the sample dimensions and mass, whilst the sintered and annealed densities were measured by the Archimedes method using mercury. The microstructures of all the specimens were examined on both fractured and sliced, polished and chemically etched surfaces using field emission gun scanning electron microscopy (FEG-SEM), the latter allowing the average grain size and grain size distribution to be determined using the linear intercept method and also the use of computer-based image processing software (Image Pro, Media Cybernetics, inc, USA). 


\section{RESULTS AND DISCUSSION}

Figure 3 shows the polished and etched microstructures at the centre of the $\mathrm{ZnO}$ disks before annealing and after annealing at $1000^{\circ} \mathrm{C}$ and $1100^{\circ} \mathrm{C}$ for 5 hours using pure conventional and hybrid heating. It can be seen that grain growth was enhanced by the use of hybrid heating, a phenomenon confirmed by the grain size data shown after 5 hours of annealing in figure 4. The figure reveals that the onset of significant grain growth during conventional heating was at around $1150^{\circ} \mathrm{C}$, whilst for the hybrid heated samples it occurred at about $1050^{\circ} \mathrm{C}$. By $1200^{\circ} \mathrm{C}$, the difference in grain size between the conventionally and hybrid annealed samples was significantly reduced, supporting the idea that microwaves have their greatest effect during the early to intermediate stages of the process [13]. This appears to be confirmed by figure 5, which shows that the slopes of the lines at 1100 and $1150^{\circ} \mathrm{C}$ were different for the conventional and hybrid cases although they were essentially the same at $1200^{\circ} \mathrm{C}$.

Table 1 shows the temperature differences that existed across the radius of the disks that were annealed for 5 hours at each of the different annealing temperatures investigated, as measured by the two optical thermometers. The difference in temperature, $\Delta \mathrm{T}$, is given by the surface temperature minus the temperature at the centre of the sample, thus an inverse temperature gradient would be visible by the presence of a negative value for $\Delta \mathrm{T}$. It can be seen that this was not found with any of the samples, the surface was always slightly hotter than the centre of the sample, particularly at the start of the annealing soak period. Although the hybrid heated samples had a smaller temperature gradient than the pure conventional heated samples, indicating that overall the samples had been slightly hotter, this was always less than $20^{\circ} \mathrm{C}$, far too little to account for the significantly larger average grain sizes at 1100 and $1150^{\circ} \mathrm{C}$.

The kinetic grain growth equation can be expressed by equation 1 [16]:

$$
G^{n}-G_{0}^{n}=K t
$$

Where $G$ is the average grain size, $n$ is an integer that depends on the diffusion mechanism, $t$ is time and $K$ can be expressed by the Arrhenius equation:

$$
K=K_{0} \exp \left(-\frac{Q}{R T}\right)
$$

where $K_{0}$ is the pre-exponential constant of the material, $Q$ the activation energy, $R$ the gas constant and $T$ the absolute temperature. Hence, the kinetic grain growth equation can be written as:

$$
G^{n}-G_{0}^{n}=K_{0} \exp \left(-\frac{Q}{R T}\right) t
$$

In this expression the initial grain size $G_{0}$ can be neglected because it is significantly smaller than the grain size $G$ at time $t$. Thus, equation 3 can be simplified to:

$$
G^{n}=K_{0} \exp \left(-\frac{Q}{R T}\right) t
$$

This has been widely applied by many researchers to calculate the grain growth exponent value $n$, e.g. [17], by plotting in the form:

$$
\log G=\frac{1}{n} \log K+\frac{1}{n} \log t
$$


Where the slope of the $\log G$ versus $\log t$ line is $1 / n$, the grain growth exponent. Hence the smaller the value of $n$, the greater the rate of grain growth.

Figure 6 illustrates the results for $\mathrm{ZnO}$ annealed at $1100^{\circ} \mathrm{C}$ whilst Table 2 shows the values for $n$ as a function of temperature. It can be seen that at 1100 and $1150^{\circ} \mathrm{C}$ they were 3.3 during pure conventional heating and 1.4 during hybrid heating respectively, whilst at $1200^{\circ} \mathrm{C}$ they both decreased to around 1.5. Many researchers have reported grain growth results during sintering of undoped $\mathrm{ZnO}$ using pure conventional heating and the value of $n$ obtained is $\sim 3$ in the $1100-1150^{\circ} \mathrm{C}$ temperature range $[18,19,20$, 21], showing good agreement with the present results. The fact that the value of $n$ at $1200^{\circ} \mathrm{C}$ during conventional heating and at $1100-1150^{\circ} \mathrm{C}$ during microwave-based heating is both lower and similar suggests that the effect of using microwaves is simply to accelerate the conventional process so that it happens roughly $100^{\circ} \mathrm{C}$ sooner, in line with the results from the sintering study [13].

\section{CONCLUSIONS}

Dense, sintered zinc oxide pellets have been annealed using both pure conventional and hybrid heating schedules involving $1 \mathrm{~kW}$ of microwave energy but in exactly the same equipment and ensuring that all the samples within each series saw exactly the same thermal history. The results showed clearly that grain growth was enhanced by approximately a factor of 3 in the range $1100-1150^{\circ} \mathrm{C}$ with hybrid heating compared to the conventional heating. Similarly, the grain growth exponent, $n$, decreased from $\sim 3$ with conventional heating to about half of this value indicating a considerable acceleration of the diffusional processes involved. Similar results were obtained by Janney et al [2] who studied grain growth in dense, fine-grained, alumina containing $0.1 \mathrm{wt} \% \mathrm{MgO}$ using conventional and $28 \mathrm{GHz}$ microwaves, though in separate furnaces. Whilst the microstructural changes that occurred were the same for both sets of samples, the grain growth kinetics were greatly increased by the microwave anneals; the grain growth rate at $1500^{\circ} \mathrm{C}$ in the microwave furnace matching that at $1700^{\circ} \mathrm{C}$ in the conventional furnace. In the present work, temperature gradients within the samples were found to be too small to explain the results, suggesting the existence of a genuine 'microwave effect' - which appears to be a simple acceleration of the conventional grain growth mechanism so that it happens at an approximately $100^{\circ} \mathrm{C}$ lower temperature. One possible explanation for the effect is the formation of Schottky defects which will enhance mass diffusion transport. Indirect experimental evidence was observed via increases in the levels of porosity in the samples. These also occurred at lower temperatures in the hybrid annealed pellets.

\section{ACKNOWLEDGMENT}

This work was supported by the Engineering and Physical Sciences Research Council (EPSRC) in the UK under grant reference GR/R52435.

\section{REFERENCES}

1. M. A. Janney and H. D. Kimrey, "Diffusion-controlled processes in microwave-fired oxide ceramics", Mat. Res. Soc. Proc., 189, 215-227 (1991).

2. M. A. Janney, H. D. Kimrey, M. A. Schmidtand and J. O. Kiggans, "Grain growth in microwaveannealed alumina", J. Am. Ceram. Soc., 74, [7] 1675-1681 (1991).

3. D. A. Lewis, "Microwave processing of polymers - an overview", Mat. Res. Soc. Proc., 269, 21-31 (1992).

4. R. J. Giguere, "Microwave assisted organic synthesis”, idem, 387-396. 
5. J. D. Katz, R. D. Blake RD and V. M. Kenkre, "Microwave enhanced diffusion?", Ceram. Trans., 21, 95-105 (1991).

6. M. Willert-Porada, T. Krummel, B. Rohde and D. Moormann, "Application of microwave heating to combustion synthesis and sintering of $\mathrm{Al}_{2} \mathrm{O}_{3}-\mathrm{TiC}$ ceramics", Mat. Res. Soc. Proc., 269, 199-204 (1992).

7. P. Boch, N. Lequeux and P. Piluso, "Reaction sintering of ceramic materials by microwave heating", idem 211-216.

8. Z. Fathi, I. Ahmed, J. H. Simmons, D. E. Clark and A. R. Lodding, "Surface modification of sodium aluminosilicate glasses using microwave energy", Ceram. Trans, 21, 623-629 (1991).

9. J. G. P. Binner, N. A. Hassine and T. E. Cross, "The possible role of the pre-exponential factor in explaining the increased reaction rates observed during the microwave syntheses of titanium carbide", J. Mat. Sci, 30, 5389-5393 (1995).

10. H. Booske, R. F. Cooper, I. Dobson and L. McCaughan, "Model of nonthermal effects on ionic mobility during microwave processing of crystalline solids", Ceram. Trans., 21, 185-192 (1991).

11. M. A. Janney and H. D. Kimrey, "Microstructure evolution in microwave sintered alumina", in Ceramic Powder Science II, Am. Ceram. Soc., 919-924 (1988).

12. M. A. Janney MA, C. L. Calhoun and H. D. Kimrey, "Microwave sintering of zirconia - $8 \mathrm{~mol} \%$ yttria", Ceram. Trans., 21, 311-318 (1991).

13. J. Wang, J. Binner, B. Vaidhyanathan, N. Joomun, J. Kilner, G. Dimitrakis and TE. Cross, "Evidence for the microwave effect during hybrid sintering", J Am Ceram Soc. 89 [6] 1977-1984 (2006).

14. I. Chen and X. Wang, "Sintering dense nanocrystalline ceramics without final-stage grain growth", Nature 404 168-70 (2000).

15. J. G. P. Binner, B. Vaidhyanathan and J. Wang, "A comparative study of temperature measurement during microwave processing", pp. 477-480, in Proc. $9^{\text {th }}$ Int Conf on Microwave and High Frequency Heating, Loughborough, UK, 477-480 (2003).

16. R. L. Coble, "Sintering crystalline solids: II Experimental test of diffusion models in powder compacts", J. Appl. Phys. 32 [5] 793-799 (1961).

17. S. J. Bennison and M. P. Harmer, "Effect of $\mathrm{MgO}$ solute on the kinetcs of grain growth in $\mathrm{Al}_{2} \mathrm{O}_{3}$ ", $J$. Am. Ceram. Soc., 66 [5] p C90-C92 (1983).

18. G. C. Nicholson, "Grain growth in zinc oxide", J. Am. Ceram. Soc., 48 [4] 214 (1965).

19. T. K. Gupta and R. L. Coble, "Sintering of ZnO: II Densification and grain growth", J. Am. Ceram. Soc., 51 [9] 521-25 (1968).

20. S. K. Dutta and R. M. Sprigs, "Grain growth in fully dense ZnO", J. Am. Ceram. Soc., 53 [1] 61-2 (1970).

21. T. Senda and R. Bradt, "Grain growth in sintered $\mathrm{ZnO}$ and $\mathrm{ZnO}-\mathrm{Bi}_{2} \mathrm{O}_{3}$ ceramics," J. Am. Ceram. Soc., 73 [1] 106-14 (1990). 
Figure 1: Example temperature - time curves used for annealing $\mathrm{ZnO}$ pellets using both a) pure conventional and b) hybrid heating, the latter involving $1000 \mathrm{~W}$ of microwave power. The level of conventional power used is also indicated.

Figure 2: Temperature monitoring system; the sample temperature is controlled by the optical fibre thermometer at the centre of the sample body.

Figure 3: FEG-SEM micrographs of the centre of the submicron $\mathrm{ZnO}$ pellets: a) before annealing and after annealing for 5 hours, b) at $1000^{\circ} \mathrm{C}$ using conventional heating, c) at $1000^{\circ} \mathrm{C}$ using hybrid heating, d) at $1100^{\circ} \mathrm{C}$ using conventional heating and e) at $1100^{\circ} \mathrm{C}$ using hybrid heating. The hybrid heating anneals involved $1000 \mathrm{~W}$ of microwave power.

Figure 4: Average grain sizes after 5 hours for annealed $\mathrm{ZnO}$ samples as a function of annealing temperature and location on the cross section of the sample (see inset) with conventional and hybrid heating.

Figure 5: Average grain sizes as a function of time for annealed $\mathrm{ZnO}$ samples after conventional (C) and hybrid $(\mathrm{H})$ heating at $1100^{\circ} \mathrm{C}, 1150^{\circ} \mathrm{C}$ and $1200^{\circ} \mathrm{C}$.

Figure 6: Log grain size versus log time for $\mathrm{ZnO}$ pellets annealed at $1100^{\circ} \mathrm{C}$ using conventional and hybrid heating. The grain growth exponents, $n$, are shown on the plot.

Table 1: Temperature differences across the $\mathrm{ZnO}$ pellets during annealing.

Table 2: Grain growth exponent values for un-doped, submicron $\mathrm{ZnO}$ as a function of temperature for conventional heating and hybrid heating. Errors are those arising from the fit to the data.

Table 3: Porosity changes in the $\mathrm{ZnO}$ pellets as a result of conventional and hybrid annealing. 


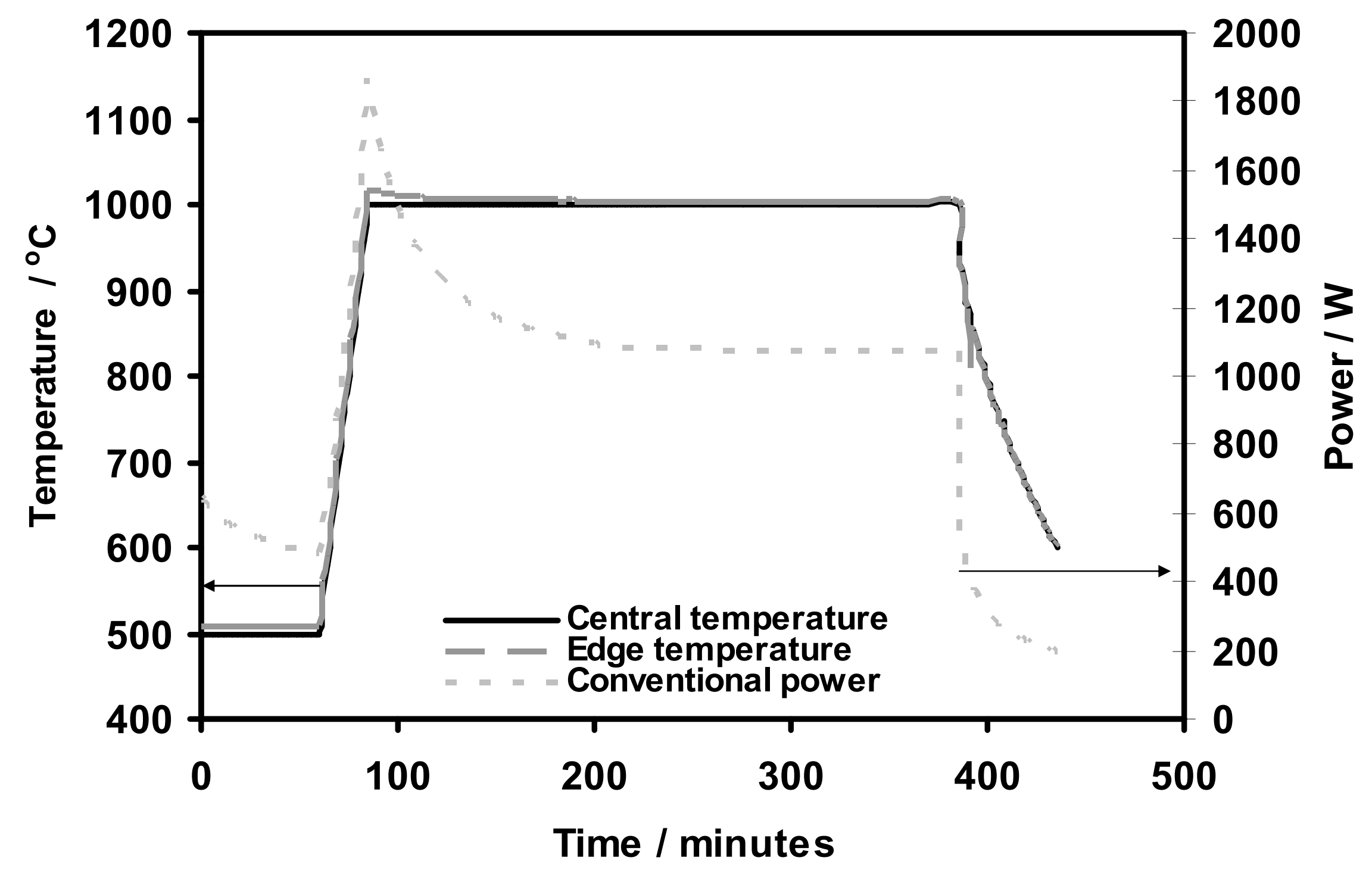

Fig 1a 


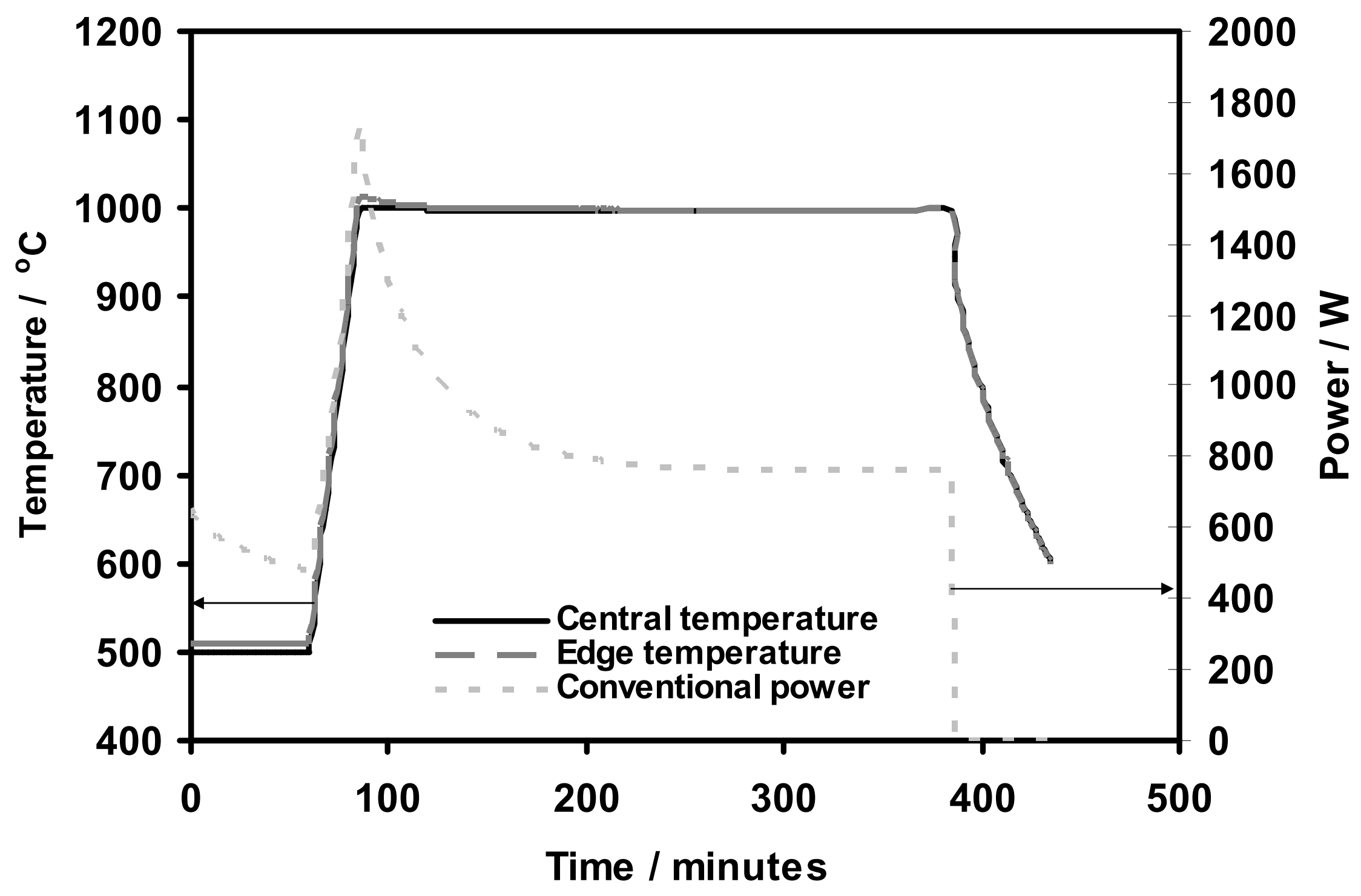

Fig 1b 


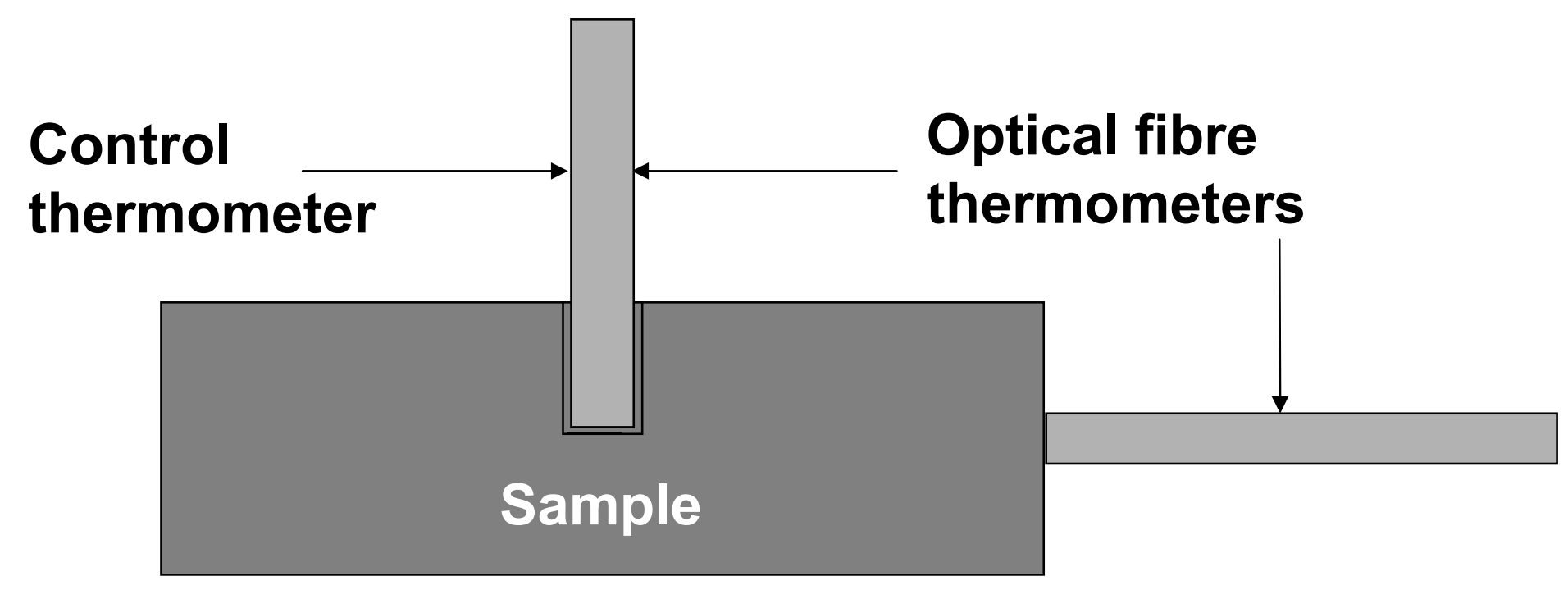

Fig 2 

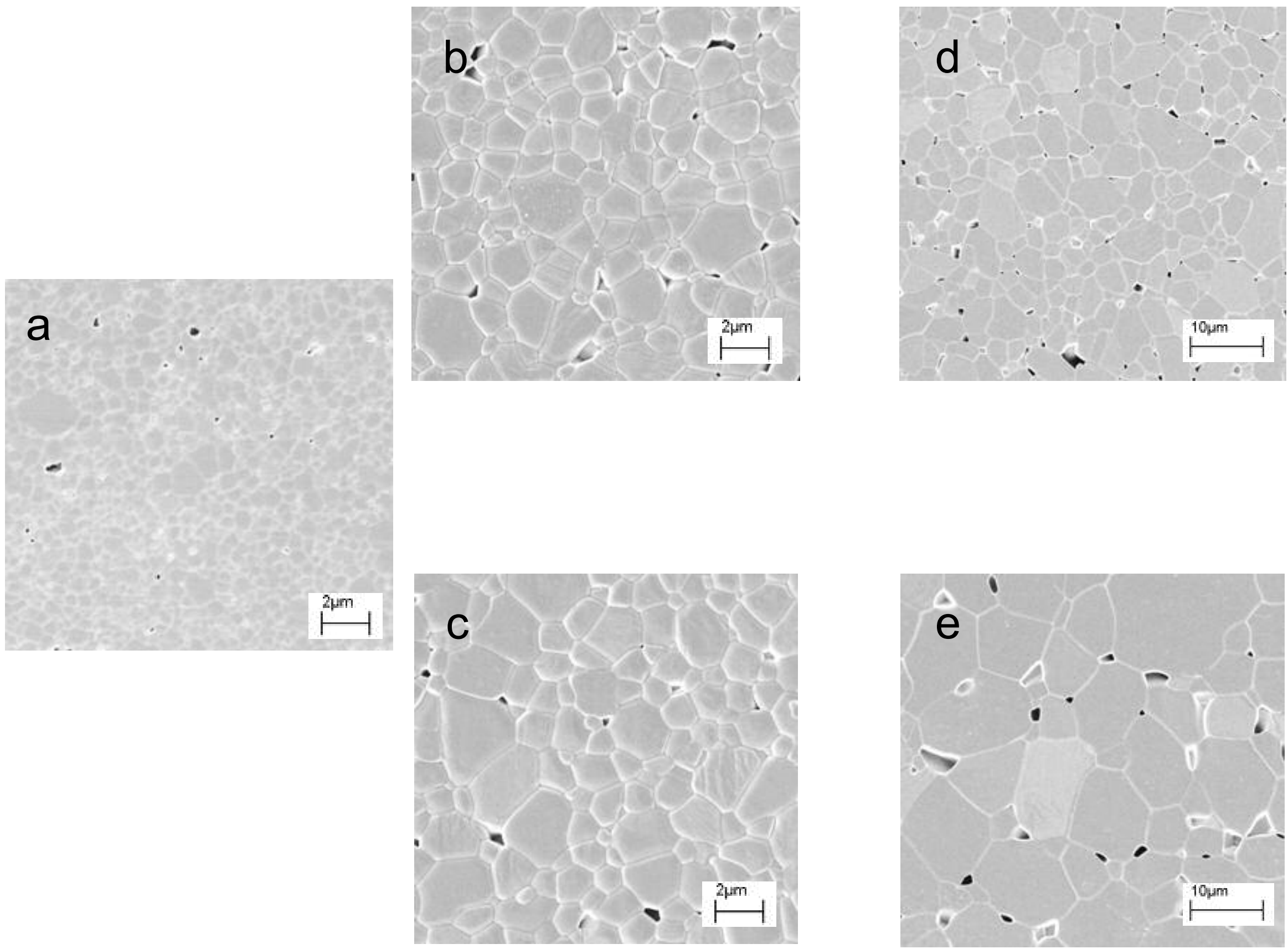

Fig 3 


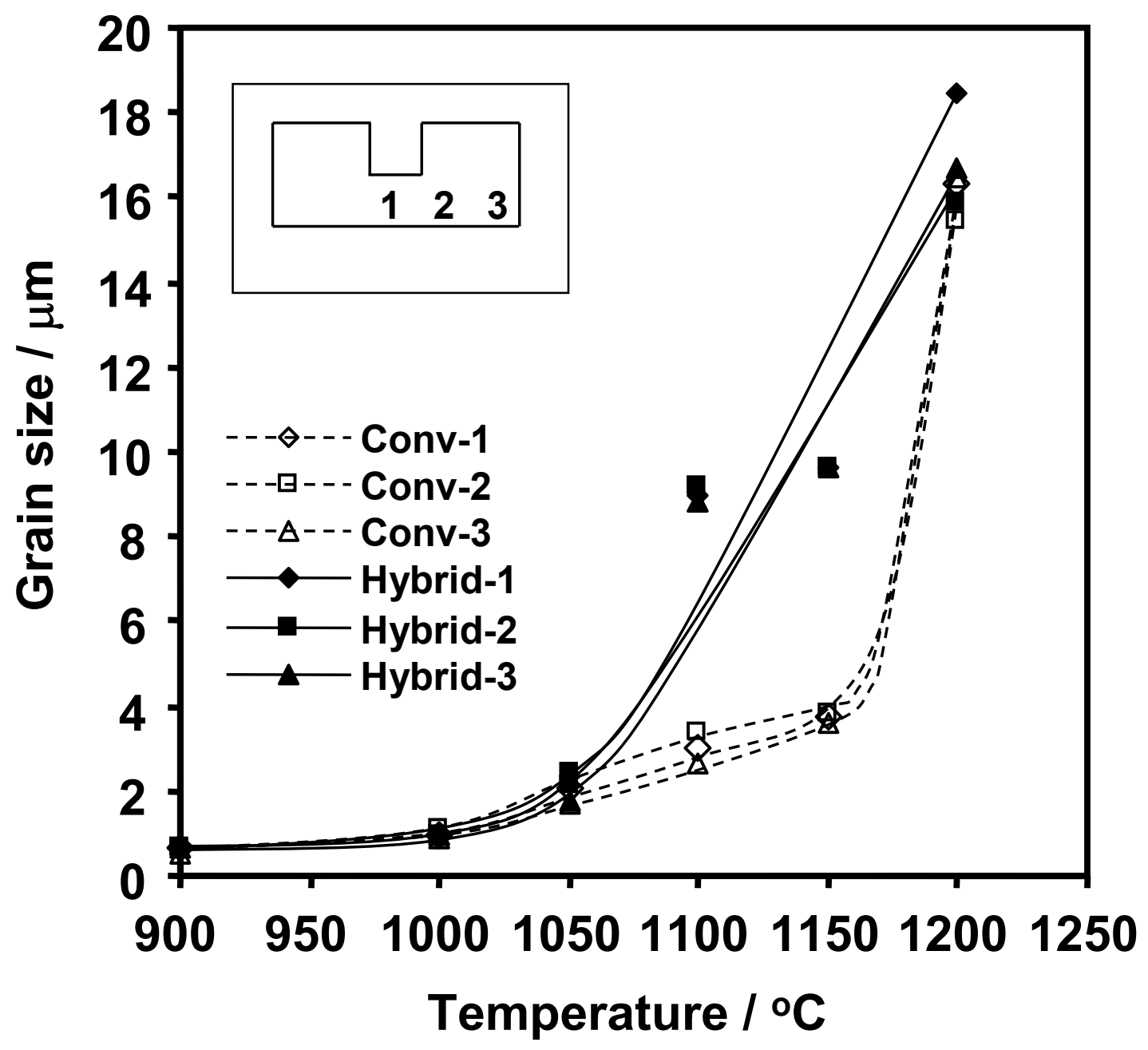

Fig 4 


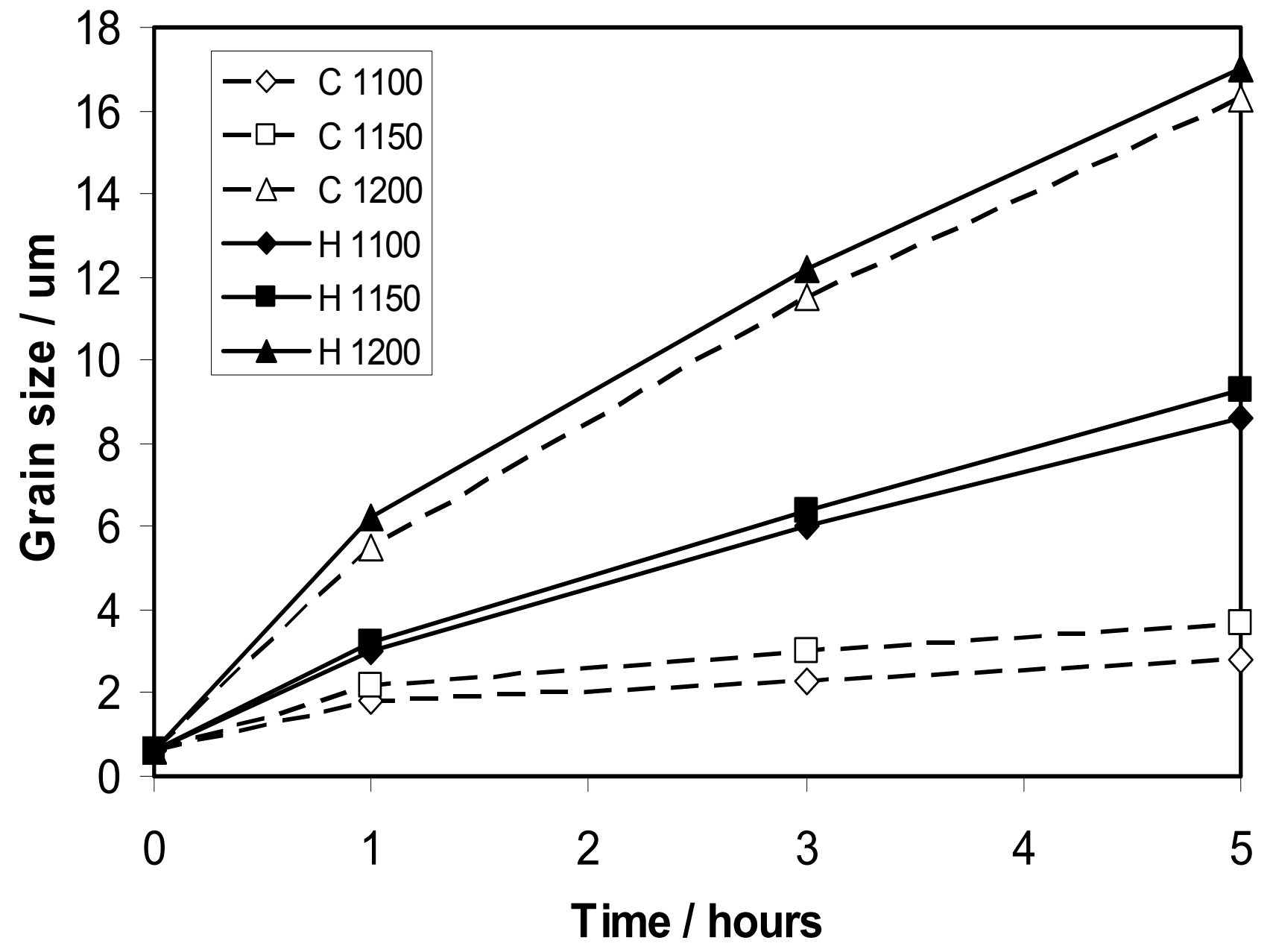

Fig 5 


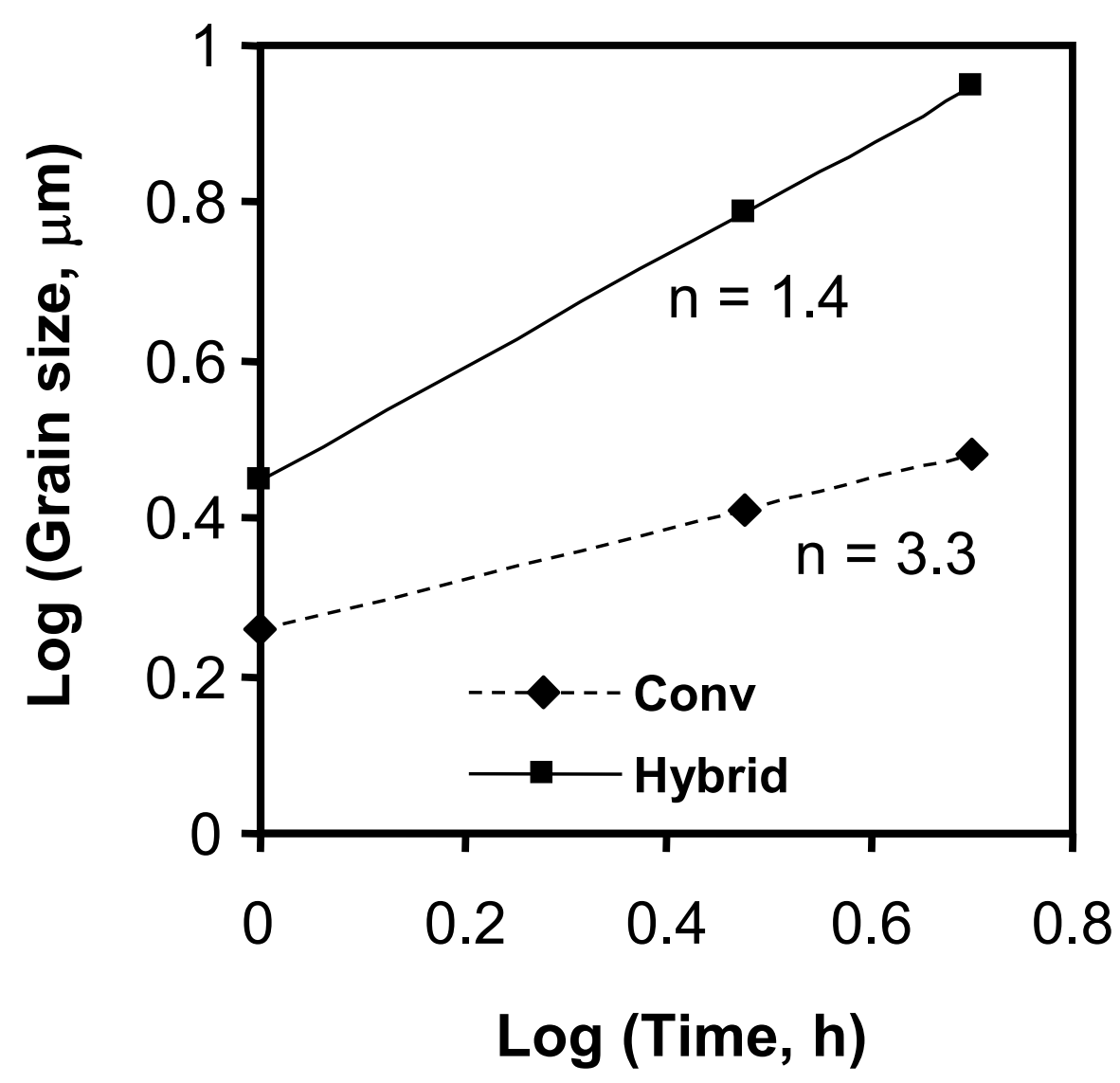

Fig 6 


\begin{tabular}{|c|c|c|c|c|}
\hline \multirow{2}{*}{ Annealing temperature $/{ }^{\circ} \mathrm{C}$} & \multicolumn{2}{|c|}{$\begin{array}{c}\text { Start of anneal soak period } \\
\Delta \mathrm{T} /{ }^{\circ} \mathbf{C}\end{array}$} & \multicolumn{2}{|c|}{$\begin{array}{c}\text { End of anneal soak period } \\
\Delta \mathrm{T} /{ }^{\circ} \mathrm{C}\end{array}$} \\
\hline & Conv & Hybrid & Conv & Hybrid \\
\hline 900 & 15 & 13 & 5 & $\mathbf{0}$ \\
\hline 1000 & 16 & 14 & 4 & $\mathbf{0}$ \\
\hline 1050 & 16 & 14 & 5 & 1 \\
\hline 1100 & 16 & 13 & 3 & 1 \\
\hline 1150 & 18 & 14 & 4 & 1 \\
\hline 1200 & 19 & 14 & 4 & $\mathbf{1}$ \\
\hline
\end{tabular}

$\Delta T=T_{s}-T_{c}$ where $T_{s}$ and $T_{c}$ are the surface and centre temperatures respectively.

Table 1.

\begin{tabular}{|c|c|c|}
\hline Annealing temperature & \multicolumn{2}{|c|}{ Grain growth exponent, $n$} \\
\cline { 2 - 3 }$/{ }^{\circ} \mathrm{C}$ & Conventional heating & Hybrid heating \\
\hline 1100 & $\mathbf{3 . 3} \pm \mathbf{0 . 1}$ & $\mathbf{1 . 4} \pm \mathbf{0 . 1}$ \\
\hline 1150 & $\mathbf{3 . 3} \pm \mathbf{0 . 1}$ & $\mathbf{1 . 4} \pm \mathbf{0 . 1}$ \\
\hline 1200 & $1.6 \pm \mathbf{0 . 2}$ & $1.5 \pm \mathbf{0 . 2}$ \\
\hline
\end{tabular}

Table 2.

\begin{tabular}{|c|c|c|c|c|c|c|c|}
\hline \multirow{3}{*}{\multicolumn{2}{|c|}{$\begin{array}{l}\text { Annealing } \\
\text { conditions }\end{array}$}} & \multicolumn{6}{|c|}{ Relative density / \% } \\
\hline & & \multicolumn{3}{|c|}{ Conventional heating } & \multicolumn{3}{|c|}{ Hybrid heating } \\
\hline & & \multirow{2}{*}{$\begin{array}{c}\begin{array}{c}\text { Before } \\
\text { annealing }\end{array} \\
98.4\end{array}$} & \multirow{2}{*}{\begin{tabular}{|c|}
$\begin{array}{c}\text { After } \\
\text { annealing }\end{array}$ \\
$\mathbf{9 8 . 9}$ \\
\end{tabular}} & \multirow{2}{*}{$\frac{\Delta}{0.5}$} & \multirow{2}{*}{$\begin{array}{c}\begin{array}{c}\text { Before } \\
\text { annealing }\end{array} \\
98.5 \\
\end{array}$} & \multirow{2}{*}{$\begin{array}{c}\begin{array}{c}\text { After } \\
\text { annealing }\end{array} \\
98.8 \\
\end{array}$} & \multirow{2}{*}{$\frac{\Delta}{0.3}$} \\
\hline $900^{\circ} \mathrm{C}$ & $5 \mathrm{hs}$ & & & & & & \\
\hline $1000^{\circ} \mathrm{C}$ & $5 \mathrm{hs}$ & 98.7 & 98.7 & $\mathbf{0}$ & 98.9 & 99.2 & 0.3 \\
\hline $1050^{\circ} \mathrm{C}$ & $5 \mathrm{hs}$ & 98.7 & 98.7 & $\mathbf{0}$ & 98.8 & 98.8 & $\mathbf{0}$ \\
\hline \multirow{3}{*}{$1100^{\circ} \mathrm{C}$} & $1 \mathrm{~h}$ & 98.9 & 98.9 & $\mathbf{0}$ & 98.9 & 98.9 & $\mathbf{0}$ \\
\hline & $3 \mathrm{hs}$ & 98.9 & 98.9 & $\mathbf{0}$ & 98.9 & 98.9 & $\mathbf{0}$ \\
\hline & $5 \mathrm{hs}$ & 98.9 & 98.9 & $\mathbf{0}$ & 98.9 & 98.4 & -0.5 \\
\hline \multirow{3}{*}{$1150^{\circ} \mathrm{C}$} & $1 \mathrm{~h}$ & 98.9 & 98.9 & $\mathbf{0}$ & 98.9 & 98.7 & -0.2 \\
\hline & $3 \mathrm{hs}$ & 98.9 & 98.4 & -0.5 & 98.9 & 98.3 & -0.6 \\
\hline & $5 \mathrm{hs}$ & 98.9 & 98.2 & -0.7 & 98.9 & 97.9 & -1.0 \\
\hline \multirow{3}{*}{$1200^{\circ} \mathrm{C}$} & $1 \mathrm{~h}$ & 98.9 & 98.0 & -0.9 & 98.9 & 98.3 & -0.6 \\
\hline & $3 \mathrm{hs}$ & 98.9 & 97.6 & -1.3 & 98.9 & 97.9 & -1.0 \\
\hline & $5 \mathrm{hs}$ & 98.9 & 97.5 & -1.9 & 98.9 & 98.3 & -0.6 \\
\hline
\end{tabular}

Table 3. 